\title{
Bai Sri Su Khwan: Spirit Blessing in North-eastern Thailand
}

\author{
Songsak Titrassamee ${ }^{1}$, Somchai Lamduan ${ }^{1} \&$ Kosit Phaengsoi ${ }^{1}$ \\ ${ }^{1}$ The Faculty of Cultural Science, Mahasarakham University, Khamriang Sub-District, Kantarawichai District, \\ Maha Sarakham Province, Thailand \\ Correspondence: Songsak Titrassamee, The Faculty of Cultural Science, Mahasarakham University, Khamriang \\ Sub-District, Kantarawichai District, Maha Sarakham Province 44150, Thailand. E-mail: stitrassamee148 \\ @hotmail.com
}

Received: April 25, $2014 \quad$ Accepted: May 28, $2014 \quad$ Online Published: June 12, 2014
doi:10.5539/ach.v6n2p134
URL: http://dx.doi.org/10.5539/ach.v6n2p134

\begin{abstract}
This is a qualitative investigation aimed at analyzing the Bai Sri Su Khwan Ceremony of Phu Tai and Tai Lao people in North-eastern Thailand. Tools used for data collection were survey, participant and non-participant observation, structured and unstructured interview, focus group discussion and workshop. Data was collected by field study and document research. The study began in October 2012 and was concluded in October 2013. Results show that the Bai Sri Su Khwan or Thai blessing ceremonies of Phu Tai ethnic groups in Isan are performed for both auspicious and inauspicious reasons. The Phan Bai Sri is a symbolic tree-like ornament used for the ceremony and a Mor Soot will lead the rites. There are seven components to the Bai Sri Su Khwan Ceremony of the Phu Tai and Tai Lao people in Isan.
\end{abstract}

Keywords: Bai Sri Su Khwan, Mor Soot, Isan, spirit, beliefs, traditional knowledge

\section{Introduction}

The people of North-eastern Thailand live in a society with deep-rooted spiritual links (Darlington, 1991). Historically the region colloquially known as Isan has been a place of intense ethnic migration and is now home to a catalogue of ethnic groups. The two largest of these are the Phu Tai and Tai Lao people, who live in a seamlessly adapted culture that comprises components of many ethnic traditions and beliefs (Thammawat, 1995). One common custom is the Bai Sri Su Khwan ceremony (Figure 1). Bai Sri Su Khwan is a blessing rite performed to the spirit. The ceremony is a generic component of many larger rituals, such as marriage and ordination (Rittenberg, 1979). It is led by a Mor Soot, a local villager with the required knowledge, expertise and experience to perform the required litany and actions throughout the ceremony.

There has been very little literature dedicated to documenting the Bai Sri Su Khwan of Phu Tai and Tai Lao people in English. Given the changing global climate that is homogenizing many aspects of Thai culture, it is necessary to investigate the specific components of traditional local customs and record their details before they are lost to history (Chompoolong, 2005; Pitakwong, 2000). With this in mind, the research team was interested in studying Bai Sri Su Khwan: Spirit blessing in North-eastern Thailand.

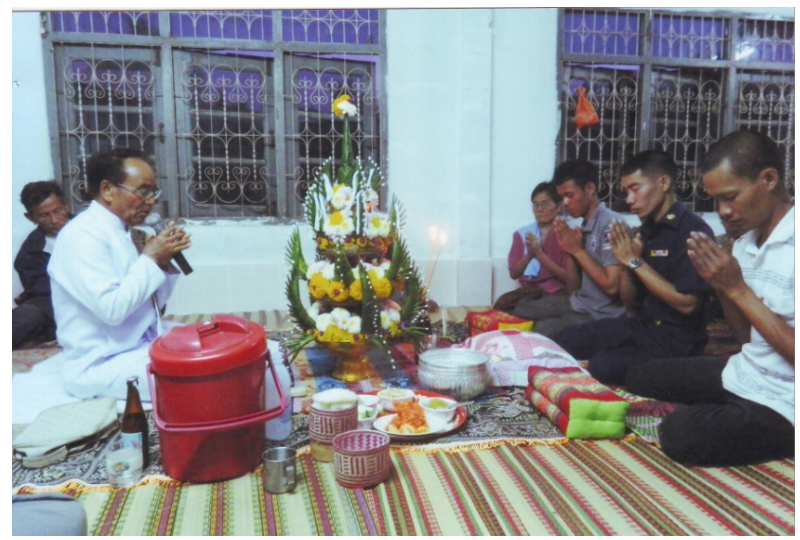

Figure 1. The Bai Sri Su Khwan ceremony, performed by a Mor Soot 


\section{Methodology}

This is a qualitative research aimed at analyzing the Bai Sri Su Khwan Ceremony of Phu Tai and Tai Lao people in North-eastern Thailand. The researchers used a purposive sampling technique to identify six villages in North-eastern Thailand as the research area. The groups chosen were: 1) Phu Tai Ban Phon, Moo 5, Ban Phon Sub-District, Kham Muang District, Kalasin Province; 2) Ban Dong Pha Yom, Moo 8, Huay Pho Sub-District, Muaeng District, Kalasin Province; 3) Ban Lao, Moo 9, Kok Phra Sub-District, Kantharawichai District, Mahasarakham Province; 4) Ban Phra Khue, Moo 3, Phra Lub Sub-District, Muaeng District, Khon Kaen Province; 5) Ban Dong Ma Eak, Moo 6, Phon Thong Sub-District, Renu Nakhon District, Nakhon Phanom Province; 6) Ban Tor Rue, Moo 5, Na Hua Bor Sub-District, Phanna Nikhom District, Sakon Nakhon Province. The research areas are located in North-eastern Thailand and are home to Phu Tai and Tai Lao ethnic groups who live in large numbers. The key informants were local philosophers, Mor Soot (a witch doctor who earns a living by restoring souls) and monks related to the Thai blessing ceremony. The casual informants were Mor Soot, Phan Buy Sri makers and Khwan owners. The general informants were people interested in the Bai Sri Su Khwan ceremony. Tools used for data collection were survey, participant and non-participant observation, structured and unstructured interview, focus group discussion and workshop. Data was collected by field study and document research. After all data had been collected, it was validated using the principles of triangulation. The research data was analyzed using analytic induction, typological analysis and constant comparison. The study began in October 2012 and was concluded in October 2013. The results are here presented as a descriptive analysis.

\section{Results}

The Bai Sri Su Khwan or Thai blessing ceremonies of Phu Tai ethnic groups in Isan are performed for both auspicious and inauspicious reasons. Auspicious reasons are to increase the chance of success in examinations or graduation, promotion to a higher rank, wedding ceremonies, ordination ceremonies and house-warming. Inauspicious reasons are illness, accident and sadness. So, the Thai blessing ceremony must be prepared to comfort people as well as provide therapy. Isan people believe recovery from illness will lead to strong mental health. The Thai blessing ceremony of Phu Tai people each district is similar. For example, the Thai blessing ceremony of Phu Tai people in Ban Phon, Kham Muang District, Kalasin Province requires a Phan Bai Sri. The Phan Bai Sri is a symbolic tree-like ornament used for the ceremony (Figure 2).

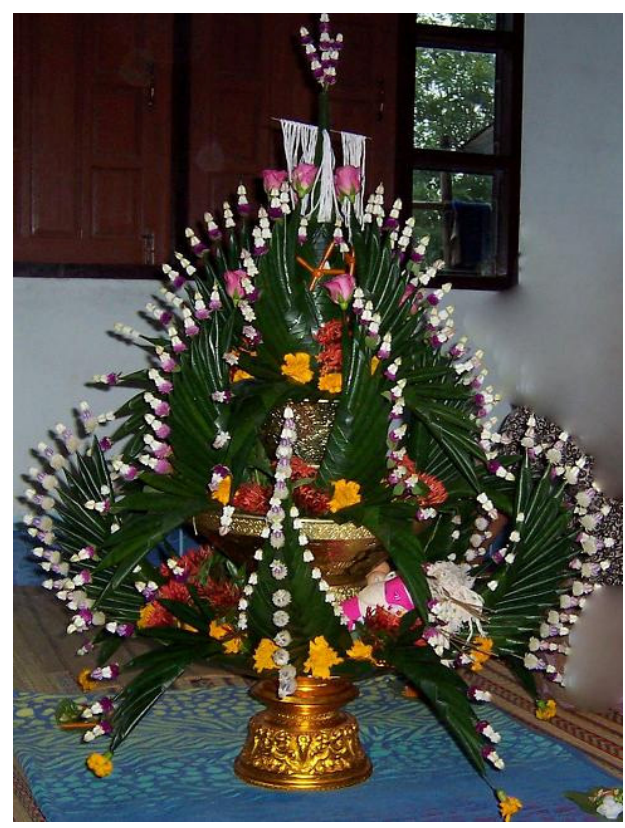

Figure 2. The Phan Bai Sri used in the Bai Sri Su Khwan Ceremony

The Phan Bai Sri is filled with milled rice, cultivated banana, Khao Tom Mat (bananas with sticky rice), desserts, joss sticks, candles, Phrawa silk textiles, scents, flowers, a cotton thread for binding the arm of the blessed, a boiled egg, an auspicious candle stand and money. The Mor Soot will lead the rites (M. Waliwan, personal communication, 2013; Figure 3). 


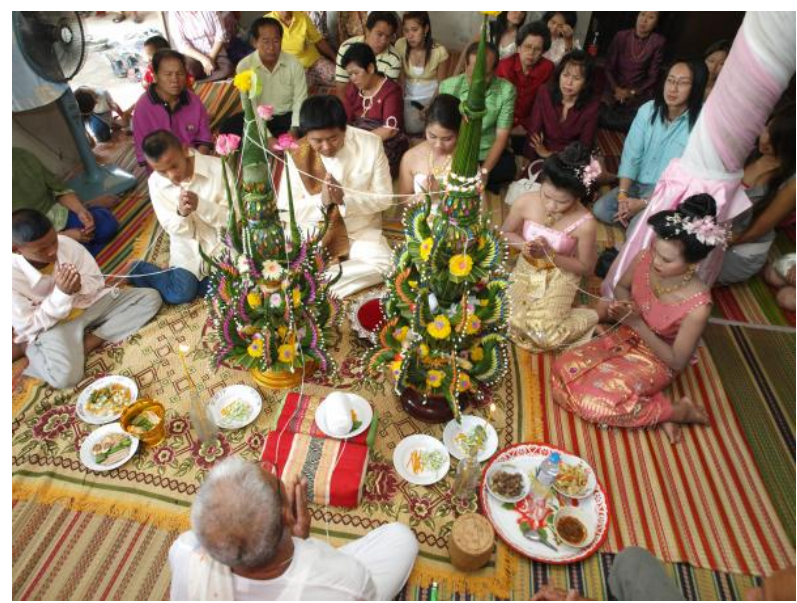

Figure 3. The Bai Sri Su Khwan Ceremony of Phu Tai people in Ban Phon, Kham Muang District, Kalasin Province

The Bai Sri Su Khwan ceremonies of Tai Lao societies in Isan hold to the belief that bad spirits incapacitate their host. If people are affected by a despondent spirit, or khwan, they will be unable to do anything. The spirit will make them afraid and sick until they die. Isan local philosophers thus invented the Bai Sri Su Khwan ceremony to help people recover from illness. There are also versions of the Thai blessing ceremony to respect buffalo for helping farmers to finish their harvest and to bless a new car or house. The intricacies of the ceremonies depend on the beliefs in each locality or community but the basic principles are similar from one community to the next. For example, the Thai blessing ceremony of Tai Lao people in Ban Dong Pha Yom, Moo 8, Huay Pho Sub-District, Mueang District, Kalasin Province has been inherited from ancestors. Nowadays the focus is on the Bai Sri Su Khwan blessing ceremony to celebrate ordination, marriage and house-warming. A village Mor Soot will leader the rites making. The villagers call the Mor Soot 'Mor Brahman' (K. Thansawing, personal communication, 2013; Figure 4).

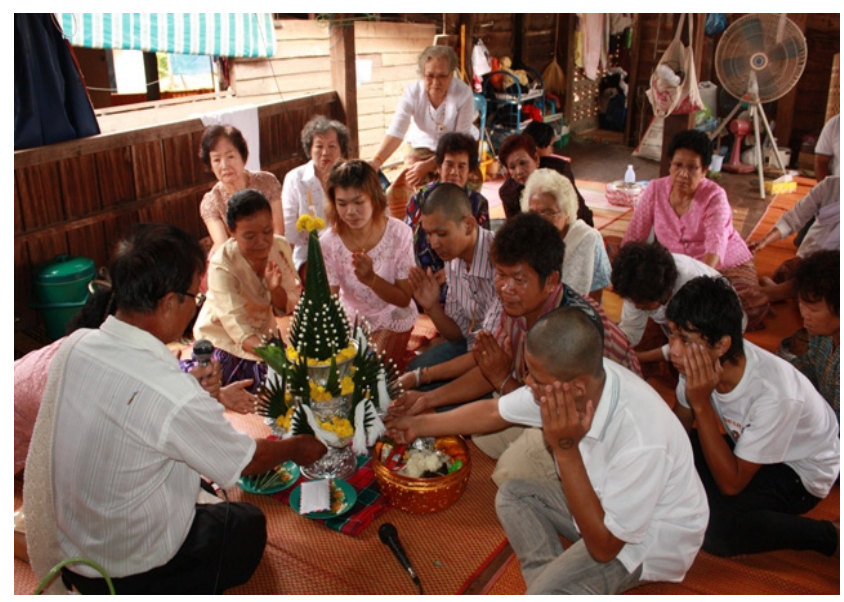

Figure 4. The Bai Sri Su Khwan Ceremony of Tai Lao people in Ban Dong Pha Yom, Moo 8, Huay Pho Sub-District, Mueang District, Kalasin Province

There are seven components to the Bai Sri Su Khwan Ceremony of the Phu Tai and Tai Lao people in Isan. 1) People: The most important individual in the Bai Sri Su Khwan ceremony is the Mor Soot or Mor Brahman, who leads the rites. The others in attendance are the person for whom the ceremony is organized and the participating audience. 2) Equipment: The two main pieces of equipment required are the Phan Bai Sri and the Phan Khao (a tray of food). 3) Capital: The host requires sufficient budget to prepare the Bai Sri Su Khwan Ceremony. 4) Environment: The date, time and location must be set in advance and agreed with the Mor Soot or Mor Brahman. 5) Rules and Manners: During the performance of the rites by the Mor Soot or Mor Brahman, all people in attendance must remain quiet and listen to the words of the ceremony. 6) Procedure: The Mor Soot or Mor 
Brahman begins the ceremony by calling to the spirit inside its host. The audience will follow the lead of the Mor Soot. The Phan Bai Sri is made and the different items are added to it in advance. These will be waiting at the agreed location for the Mor Soot. The candles and joss sticks on the Phan Bai Sri are lit and the Mor Soot performs his specific duties and chants. At the end of the rite, the host will bind cotton thread to the arm of the Mor Soot and pay the Mor Soot and appropriate amount. 7) Success: A ceremony is successful upon its completion and the completion of the act for which it is blessing. The Bai Sri Su Khwan ceremony is aimed to strengthen spiritual happiness through the traditional knowledge of Isan people.

\section{Discussion}

The Bai Sri Su Khwan ceremony in Phu Tai and Tai Lao communties in Isan has been inherited from ancestors and is commonly performed in modern society. The ceremony can be used for auspicious traditions, such as blessing a married couple, ordination, promotion, recovery from illness, graduation as a new soldier, house-warming and retirement. The Mor Soot is the leader of the rites. These findings correspond to those of Eakawit Na Thalang (2001), who studied about local wisdom in Southern Thailand. Na Thalang summarized that culture is knowledge gathered from real practices that has been inherited over a long time. It is adapted through social experimentation using knowledge and cultural trends. Traditional knowledge or local wisdom is thus tested for its use to human society and becomes a part of local culture and heritage.

The Bai Sri Su Khwan ceremony is an auspicious tradition that originated from the ideas of local philosophy. This branch of traditional psychology attests that through blessings for spirits, a person's mentality will be strengthened. People with a strong mentality will achieve success in their business endeavors and will happily coexist with others in society. These are similar to the findings of Phra Maha Thongsuk Supparo (2002), who studied the effects of Buddhism on Thai living. A focus on Buddhism is appropriate for Thai people. Even though ancient Thai people respected spirits rather than the laws of Buddhism, those beliefs are not in conflict with Buddhism at all. From the results of Supparo's study, the lives of Thai people in the realms of politics, economics, education, traditions and culture all represent and are affected by Buddhism.

The Bai Sri Su Khwan ceremony of Phu Tai and Tai Lao people in Isan will have a Mor Soot to lead the rites but still require complete sets of equipment to conduct the ceremony. The Phan Bai Sri is prepared in advance to provide a symbolic meaning of fortune to the Khwan host. For weddings, ordinations and house-warming ceremonies, the host will prepare money to pay the Mor Soot as a requirement of spiritual happiness. This is a tradition that has been inherited into present culture. Throughout the ceremony, the host and audience must listen to the Mor Soot because they will obtain knowledge to transfer to future generations. The Thai blessing ceremony consists of spirit consolation, comfort, therapy, encouragement and creation. These are positive actions that reflect the conservation and inheritance of Isan culture. Encouragement and mental health therapy help improve the patient's resilience and accelerates recovery from illness. This ceremony is attached to Isan respect for the family, adults and social manners. These findings are in agreement with those of Thongpluang Aphaiwong (2006). Aphaiwong studied therapy of patients using occultism and the ideals of Buddhist philosophy about beliefs and methods of therapy. The results show that people believe treatment in this way can cure any ill, including recovery from disease and prevention of future problems. Thus, treatment of patients using the beliefs of ancient human civilizations is anchored in psychology.

\section{Suggestions}

Following this investigation, the research team can make three suggestions for future study. First, research should be conducted into the conservation traditional treatments for mental health problems in order to reduce incorrect usage of medication and increase general knowledge. Second, further research must compare auspicious and inauspicious reasons for spiritual ceremonies and compile a catalogue of information that can be used in local communities and properly applied. Third, the history of the Isan Mor Soot should be studied to assess the role as a career and help generate a standard and stable occupation with a reasonable income.

\section{Conclusion}

The success of Phu Tai and Tai Lao Mor Soot in Isan is thanks to belief and respect in individuals with traditional knowledge and expertise. The Mor Soot are leaders of the Thai blessing ceremony and can remember the correct Thai litany and deliver it in pleasant tones according to the appropriate steps accepted by the people. They do not find success by competition and innovation, rather the traditional processes of spirit consolation, comfort, therapy, encouragement and creation.

\section{References}

Apaiwong, T. (2006). Treatment of patients with occultism and ideals of Buddhist philosophy [in Thai]. MA 
Thesis, Mahamakut Buddhist University, Bangkok.

Chompoolong, N. (2005). Traditional knowledge for education [in Thai]. Mahasarakham: Aphichat Printing.

Darlington, S. M. (1991). Buddhism, morality and change: The local response to development in Northern Thailand. Dissertation Abstracts International, 52(1), 203-A.

Na Thalang, E. (2001). Southern traditional knowledge (2nd ed.) [in Thai]. Bangkok: Amarin Book Center.

Pitakwong, J. (2000). Social and cultural change [in Thai]. Chiang Mai: Chiang Mai University.

Rittenberg, W. (1979). Formal structures of coordination in a Thai ceremony. Human Studies, 4(1), 25-36. http://dx.doi.org/10.1007/BF02127446

Supparo, P. (2002). The effect of Buddhism on Thai living [in Thai]. MA Thesis, Mahamakut Buddhist University, Bangkok.

Thammawat, J. (1995). Analysis of traditional Isan knowledge [in Thai]. Mahasarakham: Mahasarakham University.

\section{Copyrights}

Copyright for this article is retained by the author(s), with first publication rights granted to the journal.

This is an open-access article distributed under the terms and conditions of the Creative Commons Attribution license (http://creativecommons.org/licenses/by/3.0/). 